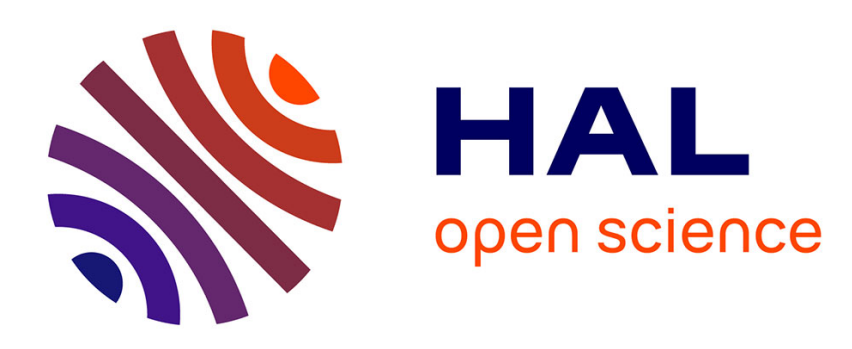

\title{
Internal Friction in Charge Density Wave (TaSe4)2 I Compound
}

\author{
H. Salva, A. Ghilarducci, F. Levy
}

\section{To cite this version:}

H. Salva, A. Ghilarducci, F. Levy. Internal Friction in Charge Density Wave (TaSe4)2 I Compound. Journal de Physique IV Proceedings, 1996, 06 (C8), pp.C8-203-C8-206. 10.1051/jp4:1996842 jpa00254650

\section{HAL Id: jpa-00254650 https://hal.science/jpa-00254650}

Submitted on 1 Jan 1996

HAL is a multi-disciplinary open access archive for the deposit and dissemination of scientific research documents, whether they are published or not. The documents may come from teaching and research institutions in France or abroad, or from public or private research centers.
L'archive ouverte pluridisciplinaire HAL, est destinée au dépôt et à la diffusion de documents scientifiques de niveau recherche, publiés ou non, émanant des établissements d'enseignement et de recherche français ou étrangers, des laboratoires publics ou privés. 


\title{
Internal Friction in Charge Density Wave $\left(\mathrm{TaSe}_{4}\right)_{2}$ I Compound
}

\author{
H.R. Salva, A. Ghilarducci and F. Levy* \\ Centro Atómico Bariloche, Av. Bustillo 9500, 8400 Bariloche, Argentina \\ * Ecole Polytechnique Fédérale de Lausanne, IPA, 1015 Ecublens, Switzerland
}

\begin{abstract}
The low frequency anelastic properties of CDW compounds near the Peierls phase transition are studied in a forced sub-resonant pendulum suitable for delicate ( $\left.\mathrm{TaSe}_{4}\right)_{2}$ I samples. The influence of measurement parameters such as frequency, oscillation amplitude, temperature rate and low temperature cycles, are obtained. The principal effects found are : the Peierls transition, a higher temperature relaxation $(\sim 260 \mathrm{~K})$ and a low temperature process $(\neg 50 \mathrm{~K})$.
\end{abstract}

\section{INTRODUCTION}

( $\left.\mathrm{Ta} \mathrm{Se}_{4}\right)_{2} \mathrm{I}$ is a well known one-dimensional charge density wave (CDW) compound but not very well studied from the point of view of its anelastic properties. Because of crystal size it was first measured in the ultrasonic frequency range by M.Saint-Paul et al [1]. Afterwards, vibrating reed experiments were performed by A.Susuki et al[2]. They measured the elastic constants in particular directions, and they obtained a reproducible reduction of the elastic stiffness constant $\mathrm{C}_{44}$ and around $0.3 \%$ reduction in the Young modulus ( $4 \mathrm{kHz})$ at the Peierls transition.

We have measured the internal friction and shear modulus of $\left(\mathrm{Ta} \mathrm{Se}_{4}\right)_{2} \mathrm{I}$ at low frequencies $(<$ $10 \mathrm{~Hz}$ ) in an inverted forced pendulum, in the temperature range from $25 \mathrm{~K}$ to $290 \mathrm{~K}$.

We present in this paper a general overview of the elastic spectrum of $\left(\mathrm{Ta} \mathrm{Se}_{4}\right)_{2} \mathrm{I}$ between $25 \mathrm{~K}$ and $290 \mathrm{~K}$ taken at $1 \mathrm{~Hz}$ and $10 \mathrm{~Hz}$, and some results in function of frequency between 0.05 and $10 \mathrm{~Hz}$.

\section{EXPERIMENTAL PROCEDURE}

Two batches of samples showing different Peierls transition temperatures (242 and 255K) were grown at the "Ecole Polytechnique Federale de Lausanne" by the conventional chemical transport method. These two batches showed the same overall features in the internal friction results. Three samples with sizes: $1 \times 1.5 \times 9 \mathrm{~mm}^{3}, 1.5 \times 1.7 \times 7.6 \mathrm{~mm}^{3}$ and $1 \times 1 \times 5.4 \mathrm{~mm}^{3}$, were measured.

Internal friction measurements were done in an inverted forced torsion pendulum [3] suitable for measurements between $0.001 \mathrm{~Hz}$ and $10 \mathrm{~Hz}$. The sample temperature could be varied from $4 \mathrm{~K}$ to $300 \mathrm{~K}$. The samples were clamped with S.P.I. silver paint in both ends and an atmosphere of $200 \mathrm{mmHg}$ of helium gas was placed between the sample and the thermometer (iron-iron/gold thermocouple).

\section{RESULTS}

Among a set of measurements, figures 1 and 2 are selected to show the experimental data at 1 and $10 \mathrm{~Hz}$ for comparing frequency effect on the internal friction spectra. Deformations of measurement must be in the order of $5 \times 10^{-5}$ or less, otherwise any jumps similar to a "serrated" effect appear in the modulus. 
In the figures we note three different kinds of perturbation. We can unambiguosly identify the Peierls transition at $242 \mathrm{~K}$, which is the same temperature detected in the electrical resistivity experiment. There are two others: one at $\sim 260 \mathrm{~K}$ which corresponds to a typical relaxation process of some entity (modulus step and an internal friction peak centered at a temperature of the maximun variation rate of the shear modulus). The other signal takes place at nearly $50 \mathrm{~K}$ and its characteristics is that we have a positive peak in internal friction and in the shear modulus. This corresponds to a hardening of the sample while a certain process is absorbing energy.

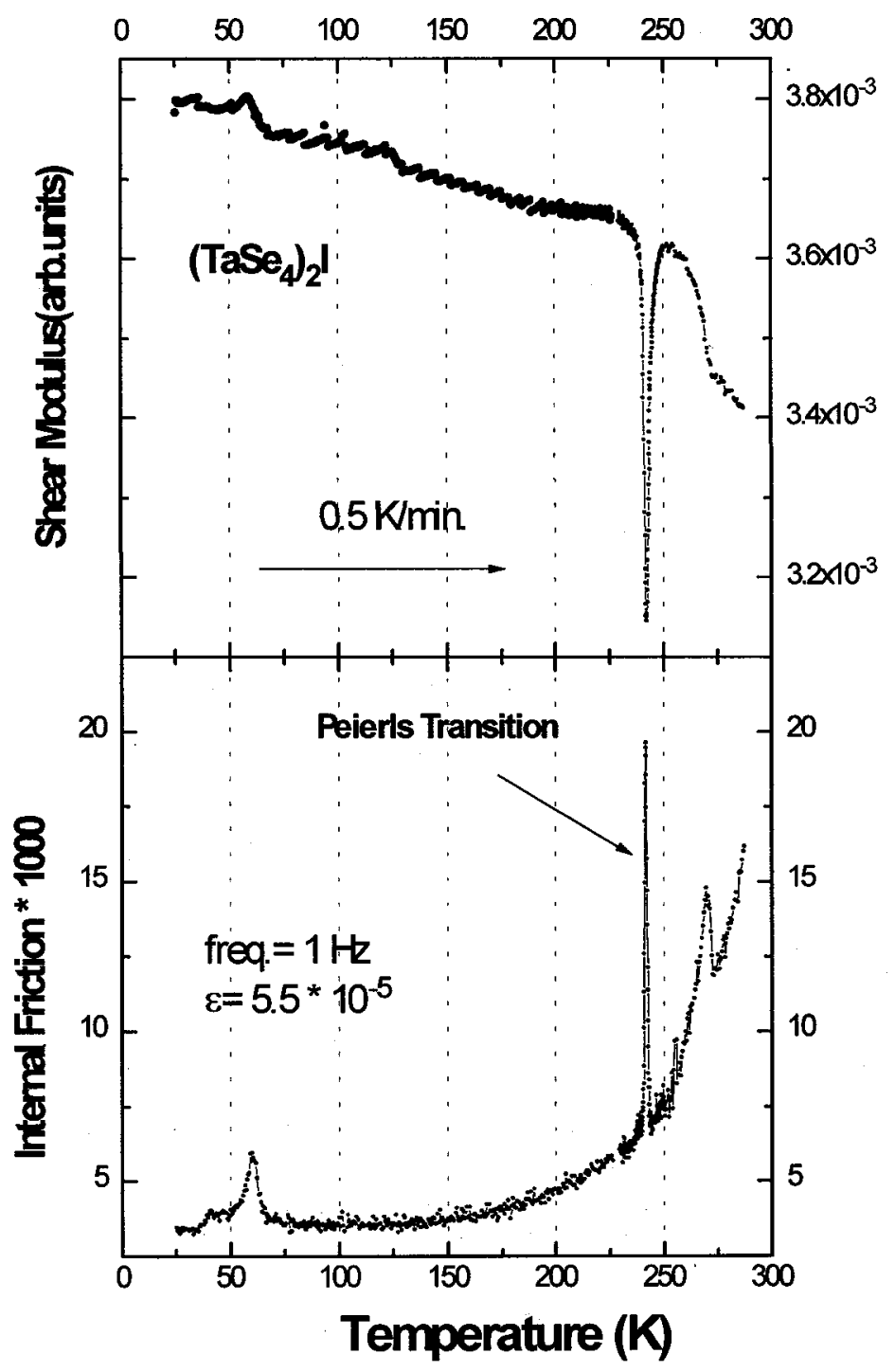

Figure 1: Shear modulus and internal friction at $1 \mathrm{~Hz}$ 
Only the Peierls transition signal is always seen in any temperature scan. The two other processes depend on the thermal history of the sample. The process at $50 \mathrm{~K}$ is never seen when decreasing the temperature.

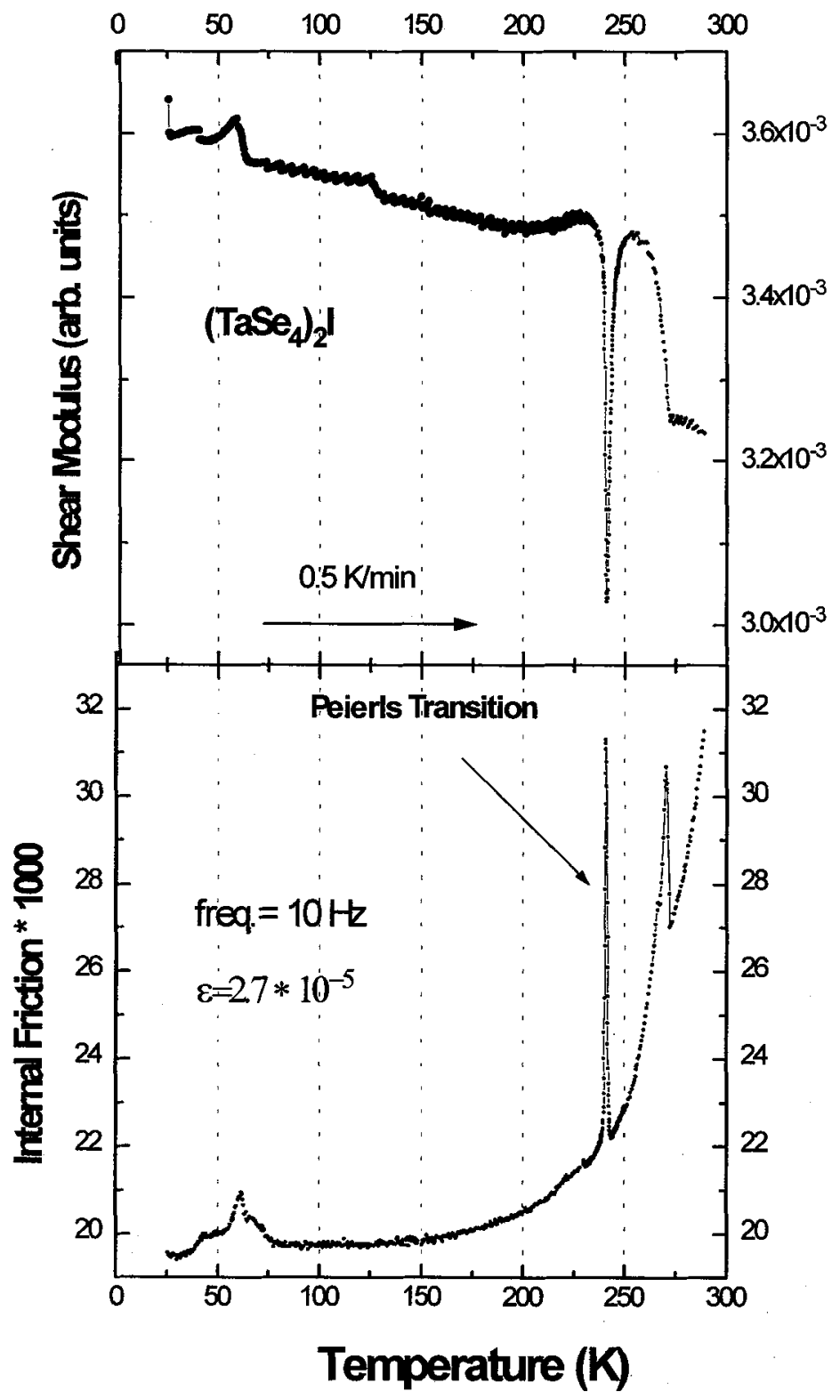

Figure 2 : Shear modulus and internal friction spectrum at $10 \mathrm{~Hz}$

In order to prove that this signal belongs to the sample, we measured a pure aluminium wire (4N) mounted in the same conditions as the sample. In this case, no variation of the shear modulus or internal friction was detected at the same temperature. 
We also made measurements at fixed temperatures ( 50 and $55 \mathrm{~K}$ ) decreasing the measuring frequency from $10 \mathrm{~Hz}$ to $0.05 \mathrm{~Hz}$. No signal was detected in this case.

The amplitude of the shear modulus or internal friction could be varied changing the temperature rate when increasing the temperature. The smaller the temperature rate, the larger the variation of anelastic properties.

The $260-270 \mathrm{~K}$ relaxation has a small dependence on the measuring frequency. This dependence gives an energy barrier of nearly $1 \mathrm{eV}$. Like the process of low temperature, this relaxation of $260-270 \mathrm{~K}$ is not always seen when decreasing the temperature, and it is necessary to reach at least $100 \mathrm{~K}$ to observe this effect increasing the temperature.

\section{DISCUSSION AND SUMMARY}

An exhaustive analysis of the Peierls transition characteristics was made elsewhere[4], that we summarize as follows:

1) Well repetitive simultanous effects at $T p$ : a sharp internal friction peak $\left(Q^{-1}\right.$ maximun $\left.\sim 10^{-2}\right)$ and an important elastic shear modulus variation $(\Delta G / G \sim 12 \%)$ are observed. The latter is greater than the Young modulus variation detected in vibrating reed experiments ( $\Delta \mathrm{E} / \mathrm{E} \sim 0.1$ to $1 \%$ ) [2] and in concordance with the fact that in ultrasonic experiments [1] the $\mathrm{C}_{44}$. was the stiffness constant most affected $(\sim 2.7 \%)$.

2) Their dependence with oscillation amplitude is different: the internal friction peak variation $\left(\Delta Q^{-1}=\right.$ $\mathrm{Q}^{-1}$ maximun $-\mathrm{Q}^{-1}$ background) at $\mathrm{Tp}$ increases linearly with amplitude $\varepsilon$ between 1 to $5.5 \times 10^{-5}$, but the $\triangle \mathrm{G} / \mathrm{G}$ modulus variation does not change.

3) Succesive temperature scans do not alter the effects, only a slightly decrease in Tp is observed $(\sim 2 \mathrm{~K}$ after 5 low temperature cycles).

4) Torsion measurement problems in this compound lead us to scan at a temperature rate $\mathrm{dTp} / \mathrm{dt}=0.1 \mathrm{~K} / \mathrm{min}$ in the transition temperature range $(230$ to $260 \mathrm{~K})$.

We are still measuring the processes of lower and higher temperature than the Peierls transition. We think that the higher one may be due to a relaxation of iodine, which in this compound is very unstable. At this time we have no model of the origin of the low temperature process. Measurements are in course to deny the possibility that helium gas from the thermalization atmosphere enters the sample when we decrease the temperature and then at $50 \mathrm{~K}$ it comes out giving a hardening of the sample.

\section{ACKNOWLEDGEMENTS}

The authors are gratefull to Mr.H.Berger in preparing the samples at the "Ecole Polytechnique Federale de Lausanne", Switzerland. This work was partially supported by PIA 340/92 from CONICETArgentina.

\section{REFERENCES}

[1] Saint-Paul M., Monceau P. and Levy F., Solid State Comm. V.67(6) (1988) 581-584

[2] Suzuki A., Mizubayashi H. and Okuda S., J. of the Phys.Soc. of Japan. V.57(12) (1988) 4322-4333.

[3] D'Anna G. and Benoit W., Rev.Sci.Instrum. V.61 (1990) 3821-

[4] Salva, H.R., Ghilarducci A.A. and Levy F., submitted to Solid State Comm. 